\title{
Arquivos de fotógrafos profissionais de eventos sociais: um estudo de caso
}

Archives of professional photographer firms specialized in social events: a case study

\author{
Eliana Kátia PupIM (1) e Telma Campanha \\ de Carvalho MADIo (2)
}

(1) UNESP, Faculdade de Filosofia e Ciência de Marília, Departamento de Ciência da Informação Programa de Pós-Graduação em Ciência da Informação, Av. Hygino Muzzi Filho, 737, katia_pupim@hotmail.com. (2) telmaccarvalho@marilia.unesp.br

\begin{abstract}
Resumen
Se presenta una propuesta para organizar los archivos de las empresas de los profesionales de la fotografía especializados en eventos sociales. Se trata de un estudio de caso realizado en una empresa de la Turística de Tupã, en el Estado de São Paulo, una ciudad con una gran tradición en el gremio.
\end{abstract}

Palavras chave: Archivos fotográficos. Archivos empresariales. Ciencia da Información. Archivología. Fotografía. Brasil.

\section{Introdução}

O presente trabalho pretende contribuir para 0 desenvolvimento de material teóricometodológico que possibilite caminhar tanto na compreensão hermenêutica, como na crítica dialética da interdisciplinaridade entre a Ciência da Informação e a Arquivologia, destacando sua relevância para a organização de arquivos fotográficos privados, sensibilizando pesquisadores e profissionais da Ciência da Informação a voltarem seu olhar para o tema em destaque. Para tanto, embasa-se em teorias da Ciência da Informação com o objetivo de conhecer a situação em que se encontra o arquivo fotográfico de uma das maiores empresas do ramo fotográfico de eventos da região de Tupã, Estância Turística localizada no centro-oeste do Estado de São Paulo, Brasil, a Empresa Multicolor Formaturas e Eventos, de forma que se possa ao final dos estudos oferecer subsídios teóricos e práticos para os profissionais que tencionem atuar nesta área. Em razão do exposto, propõe-se: a) investigar a partir dos documentos e registros existentes, de observação in loco das rotinas e de entrevistas às pessoas que tenham algum vínculo com o arquivo, o contexto em que o arquivo se insere, seu posicionamento dentro da em-

\begin{abstract}
A proposal to organize the archives of professional photographer firms is presented, based in a case study of a firm specialized in photographing social events in the Estância Turística de Tupã, in the state of São Paulo, Brazil, a city with a long tradition in the industry.
\end{abstract}

Keywords: Photographic archives. Business archives. Information Science. Archivology. Photography. Brazil.

presa, quais as necessidades dos usuários sobre $o$ arquivo fotográfico da empresa privada; $b$ ) desenvolver, mediante os dados coletados, tanto pela pesquisa bibliográfica, pelas observações efetuadas in loco e pelos questionários aplicados, um diagnóstico que possa ser relevante para a efetiva implementação e melhoria do arquivo; c) construir subsídios teóricometodológicos que contribuam para que graduandos em Ciência da Informação, pesquisadores e demais pessoas interessadas em estudar o tema possam conhecer e projetar qual será o futuro destes grandes arquivos fotográficos na era da fotografia digital.

O estudo se sustenta pela necessidade da presença do profissional da Ciência da Informação neste setor de produção, pois, detecta-se uma latência por profissionais que compreendam em profundidade os valores primários e secundários dos documentos, que contribuam efetivamente para a organização do arquivo fotográfico privado e que, através de sua intervenção construa um grau de entrosamento interdisciplinar que possibilite uma atuação eficiente, eficaz e duradoura.

A relevância social do estudo de arquivo fotográfico de empresa privada se dá através da 
proximidade de um vínculo concreto entre o profissional em Ciência da Informação e o pólo fotográfico existente na região, abrindo canais promissores de intercâmbio em área tão pouco explorada entre empresa e profissionais da $\mathrm{Ci}$ ência da Informação.

A importância científica poderá ser avaliada mediante o construto de conhecimentos que abordem conteúdos da Ciência da Informação, gestão do conhecimento, gestão da informação e arquivologia, incentivando a discussão interdisciplinar sobre a gestão de fundos fotográficos, sejam eles públicos ou privados.

Para alcançar os objetivos propostos optou-se por desenvolver a metodologia de estudo de caso, tencionando contextualizar o arquivo fotográfico de empresa privada do setor de eventos.

$O$ estudo tem como recorte teórico o arquivo fotográfico privado da Empresa Multicolor Formaturas e Eventos, empresa fotográfica especializada na cobertura fotográfica e filmagem de eventos do tipo formatura, contando com mais vinte e três anos de existência atendendo ao mercado nacional.

A observação aliada à entrevista aberta foram os instrumentos escolhidos para a coleta de dados, a serem aplicados aos diretores da empresa, aos funcionários e usuários do arquivo.

Tentar-se-á conjugar, então, os principais pontos intercorrentes do trabalho, com base na argumentação teórica e na interação prática. Nesse sentido, as hipóteses que norteiam a pesquisa são a falta de conhecimento por parte dos empresários das competências do profissional da informação, ou uma lacuna na formação desses profissionais que os inibam de atuarem nos arquivos fotográficos empresariais.

Com a intenção de melhor compreender os conceitos imbricados no estudo houve a necessidade de conhecer, mesmo que brevemente, a evolução histórica e tecnológica da fotografia ocorrida em concomitância com o desenvolvimento da sociedade. Após esse resgate, retomam-se alguns aspectos epistemológicos da Ciência da Informação juntamente com a Arquivologia que contribuiram para o entendimento e a discussão do tema abordado. Expõe-se rapidamente a metodologia escolhida para a confecção do trabalho e, finalmente, considera-se alguns pontos já alcançados pelo estudo.

\section{Contexto da pesquisa}

Como cenário deste estudo apresenta-se a cidade de Tupã, município reconhecido por uma longínqua tradição empresarial no ramo fotográ- fico, explorada desde meados do século XX. Vê-se que, logo após o auge da difusão da fotografia em países europeus como a França, Alemanha, Inglaterra, e outros países considerados desenvolvidos como também os Estados Unidos da América, a técnica ou como alguns teóricos preferem, a arte da fotografia logo também se fazia presente nos rincões mais profundos do Brasil, mais especificamente no centro oeste paulista, onde era dado início a um período de desbravamento para a implantação das lavouras cafeeiras.

$\mathrm{Na}$ instalação do Distrito de Tupã, município de Glicério e Comarca de Penápolis, ocorrido em 12 de Outubro de 1935, ainda não havia profissional capacitado para registrar o fato através de fotografias, ocasião em que foi chamado o fotógrafo mais próximo que no momento residia no município de Quatá, cidade vizinha a Tupã, e seu nome era Eufrenias, mais conhecido como "seu Frenias". Para se registrar festividades oficiais, casamentos, batizados criou-se até um bordão "Chame o seu Frenias", para dizer que um fato era importante (Sao Paulo, 2001, p. 30).

O primeiro fotógrafo a residir em Tupã foi José Galante e a partir de 1938 se tornou o fotógrafo oficial e também o leiloeiro das quermesses locais, o que o tornava conhecido nas diversas esferas da iniciante sociedade tupãense. Com a instalação da Comarca de Tupã, por volta de 1945, passou a ser o Primeiro Oficial de Justiça do Município deixando o ofício de fotógrafo (São Paulo, 2001, p. 30).

O primeiro ateliê de fotografia tupãense foi aberto em 1945, na Avenida Tamoios. Denominado Foto Nito era de propriedade do fotógrafo profissional japonês de mesmo nome que foi assassinado em 1948 pelos fanáticos da Toko-tai (1), a causa de sua morte era acreditar na derrota do Japão. Antes de seu falecimento o fotógrafo Nito transmitiu sua arte ao então aprendiz, Sakae Ishida, personagem de grande relevância para o desenvolvimento da fotografia em Tupã (São Paulo, 2001, p. 30).

Sakae Ishida e seus familiares chegaram ao Brasil em 1934 para trabalhar nas lavouras da região, o primeiro contato com a fotografia se deu em 1941, quando iniciou a aprendizagem da arte fotográfica e suas técnicas com o mestre Nito. Após a lacuna deixada pela morte de seu mestre, Sakae abriu o Foto Avenida em 1949, atualmente chamado de Cine Foto Ishida, dirigido por seu filho Eliseo Ishida. Os trabalhos de Sakae eram reconhecidos em todo o território brasileiro, repercutindo em veículos de comunicação de circulação nacional, como a revista Manchete de julho de 1959, que mostrou foto- 
grafias de sua autoria que ilustravam matéria sobre a cidade de Tupã, naquela época era a cidade que mais crescia no Brasil (São Paulo, 2001, p. 31).

Por sua vez, os irmãos e sócios Jorge e Eizi Hirano, em 1948 estabeleciam a Foto Ideal, também na principal rua da cidade, a Avenida Tamoios, onde permaneceram até o início da década de sessenta. A empresa apostou e desenvolveu um projeto até então inusitado, a cobertura fotográfica para debutantes, casamentos e formaturas. Com isso, alavancaram a cobertura de eventos por todo o território brasileiro, criando a Companhia Fotográfica Hirano, tornando-se uma empresa pioneira e a maior do setor até o encerramento de suas atividades. A Companhia Fotográfica Hirano teve a função de escola para as atuais empresas do ramo de fotografia, tanto os empreendimentos locais como até mesmo empresas estabelecidas em outros estados. Foram os irmãos Hirano que ao investirem maciçamente nesse tipo de cobertura proporcionaram a Tupã o título de Capital Brasileira das Fotos de Eventos (São Paulo, 2001, p. 31).

Atualmente, a Empresa Multicolor Formaturas e Eventos é considerada pelos profissionais da área como a maior empresa da área de fotografia do ramo de eventos da região. Seus sócios, que fizeram parte da equipe de profissionais da Cia. Hirano, iniciaram os trabalhos da empresa através de cobertura de eventos sociais nas cidades de São Paulo, Paraná, Minas Gerais, Rio de Janeiro, Mato Grosso, Mato Grosso do Sul, Goiás, Bahia. E hoje, com mais de vinte anos de atuação no mercado seus contratos correspondem a $70 \%$ do mercado brasileiro de cobertura de eventos (São Paulo, 2001, p. 32).

Pelo exposto conclui-se que o interesse tupãense sobre a produção e a comercialização da fotografia formalizou-se em 1945 com a criação do Foto Nito e logo em seguida pela instalação do Foto Avenida, havendo uma grande euforia fotográfica com a constituição da Companhia Fotográfica Hirano, pioneira na cobertura de grandes eventos. Atualmente a Empresa Multicolor é considerada a herdeira do empreendedorismo da extinta Cia. Hirano, mas há espaIhadas pelo território nacional, inúmeras outras empresas cuja origem se deu através dos antigos funcionários da Hirano.

Hoje em Tupã, há a presença de cerca de mil profissionais da fotografia, distribuídos entre aproximadamente quarenta empresas de pequeno, médio e grande porte. Apesar de não existir parâmetros corretos para cálculos, presume-se que esse montante de fotógrafos, em conjunto com suas empresas, gera milhões de fotos por ano, e todas as empresas produzam um acervo fotográfico sem limites previsíveis.

O segmento fotográfico existente na cidade de Tupã apresenta diversas possibilidades de atuação, como também de pesquisa, para os profissionais da Ciência da Informação, possibilitando o estudo do comportamento de tal acervo e proporcionando aos profissionais se adequarem às novas estruturas, formatos e requisitos que estão por vir, caso contrário correrão o risco de ter seus espaços na organização, administração e gestão de informações iconográficas ocupados por pessoas ligadas mais intimamente à linha de produção dessas imagens.

Para tanto, entende-se que se faz necessário aprofundar um pouco mais sobre o objeto fotografia e sua relevância social.

\section{A evolução social da fotografia}

A fotografia é indício de informação sobre vários momentos da humanidade: de um simples registro de família como casamento, nascimento ou uma formatura; também perpetua fatos que sejam de interesse de uma comunidade como eleições ou inaugurações, entre outros eventos. Registra ocorrências de interesse de toda a raça humana como as tempestades, furacões, vulcões, e também preserva as invenções do homem entre os quais lançamentos de foguetes, explosões atômicas, e catástrofes como as guerras.

Em época recente, a fotografia tornou-se um passatempo quase tão difundido quanto o sexo e a dança - o que significa que, como toda forma de arte de massa, a fotografia não é praticada pela maioria das pessoas como uma arte. É, sobretudo, um rito social, uma proteção contra a ansiedade e um instrumento de poder. Comemorar as conquistas de indivíduos tidos como membros da família (e também de outros grupos) é uso popular mais antigo da fotografia (Sontag, 2004, p. 18-19).

A fotografia possibilitou grandes evoluções em muitas áreas, mas seu maior impacto foi nas artes. A história nos conta que a xilogravura, originada na Idade Média, foi a primeira técnica empregada que possibilitou a reprodutibilidade do desenho, antes mesmo da invenção da imprensa de Gutemberg. Após a xilogravura, surgiram a estampa em chapa de cobre, a águaforte e a litografia. A litografia por sua vez contribuiu muito para o desenvolvimento das artes gráficas, mas com o advento da fotografia sua atuação foi breve (Benjamin, 1993, p. 166). 
Pela primeira vez no processo de reprodução da imagem, a mão foi liberada das responsabilidades artísticas mais importantes, que agora cabiam unicamente ao olho. Como o olho apreende mais depressa do que a mão desenha, o processo de reprodução da imagem experimentou tal aceleração que começou a situar-se no mesmo nível que a palavra oral (Benjamin, 1993, p. 166).

A imagem fotográfica é a imagem da modernidade (Barthes, 1984, p. 21).

Tecnicamente, a fotografia está no entrecruzamento de dois processos inteiramente distintos: um é de ordem química: trata-se sobre a ação da luz sobre certas substâncias; outro é de ordem física: trata-se da formação da imagem através de um dispositivo óptico.

O que a fotografia registra só ocorre uma vez, por mais que a situação se repita o referente estará transformado, não será o mesmo (Barthes, 1984).

Os recursos fotográficos hoje são empregados em todas as áreas possíveis: na academia, na indústria e na sociedade como um todo. A fotografia, presente nas diversas esferas da sociedade é tão constante que passou a não ser notada e os indivíduos a aceitam apenas e não refletem sobre suas razões e interesses.

Partamos do ponto de criação da máquina fotográfica que aconteceu na França, pelo trabalho de Nicéphore Niépce em 1826. Em 1839, foi por intermédio do parlamentar François Arago intelectual pertencente à Câmara que vislumbrou suas inúmeras possibilidades de aplicação principalmente nas ciências - que a máquina fotográfica passou a ser objeto de domínio público, com essa atitude a intenção do Estado era de que esta máquina e seus usos fossem explorados pela sociedade em geral.

O novo invento de imediato causou algum espanto, pois uma das teorias especulativas que explicavam a fixação da imagem no papel era que a alma ou parte dela era capturada através do disparo do obturador da máquina. Logo após esta primeira impressão equivocada, foi tratada mais seriamente como método de pesquisa, já que comprovava situações e fatos ocorridos, provocando uma verdadeira euforia fotográfica.

Em 1855, o fotógrafo alemão Hampstangl demonstra suas descobertas de processos que possibilitavam a manipulação do resultado fotográfico, exibindo fotos com e sem retoques, possibilitando assim a confecção das fraudes, destitui da fotografia a característica de reprodução fiel do referente (Freund, 1995).
Desde seu aparecimento a foto é passível de distorções e, com os programas de computador disponíveis atualmente, há uma facilidade que proporciona a disseminação dos processos de manipulação das imagens por qualquer indivíduo, mas, necessariamente para que indivíduos utilizem os programas de computadores e manipulem as imagens, há o pressuposto de que em algum momento a imagem daquele significante existe, ou existiu, e era semelhante ao que está registrado na imagem (Sontag, 2004, p. 16).

As fotos, que brincam com a escala do mundo, são também reduzidas, ampliadas, recortadas, retocadas, adaptadas, adulteradas. Elas enveIhecem, afetadas pelas mazelas habituais dos objetos de papel; desaparecem; tornam-se valiosas e são vendidas e compradas; são reproduzidas. Fotos, que enfeixam o mundo, parecem solicitar que as enfeixemos também. São afixadas em álbuns, emolduradas e expostas em mesas, pregadas em paredes, projetadas como diapositivos. Jornais e revistas as publicam; a polícia as dispõe em ordem alfabética; os museus as expõem, os editores as compilam (Sontag, 2004, p. 15).

No início do século XIX, com a ascensão e expansão da classe burguesa, sua presença nas esferas econômicas e sociais se tornava cada vez mais destacada, e a representação da posição que alçou se deu através do retrato, que procurava aliar a burguesia aos elementos do modelo de domínio de então, a aristocracia. A sobrevivência da classe artística estava ligada à necessidade de adequação ao gosto desta nova clientela, o que foi possível através da fotografia (Freund, 1995).

Observamos que a primeira forma de lastro da fotografia foi o retrato fotográfico, categoria que teve início na França com a burguesia e se expandiu pelo mundo todo. Os primeiros fotógrafos eram os pintores que se aventuravam a conhecer as novas técnicas, citamos pintores fotógrafos deste momento: Félix Tournachon Nadar, os irmãos Bisson, Gustave Le Gray, entre outros. Para esta geração de fotógrafos, o resultado era a fixação de um aspecto do caráter do retratado que traduzia sua personalidade. Como os artistas estavam mais preocupados com a arte da fotografia primavam pela qualidade e por não se aterem aos lucros, não lograram êxito econômico com a atividade (Freund, 1995).

A fotografia é contemporânea do capitalismo, e como em todas as formas de expressão, encontramos os verdadeiros talentos e os oportunistas. Baudelaire atacava o público que se debru- 
çava sobre as imagens fotográficas, um público muito maior do que o apreciador de obras de arte e principalmente de menor cultura.

Havia brados veementes contra a fotografia, entretanto, independente de ser arte ou não arte, o novo ramo prometia grandes lucros, com isso uma grande parcela de desempregados e falidos procurava na fotografia sua fonte de rendas devido à relativa facilidade de manuseio da máquina. Ressaltamos que, apesar da máquina fotográfica ser manuseada por pessoas sem muito preparo, é necessário enfatizar que estes novos fotógrafos não dominavam os conceitos artísticos inerentes aos pintores, o que contribuía para o estigma negativo que obteve a fotografia entre os artistas e intelectuais da época.

O percurso da fotografia acompanha o desenvolvimento tecnológico apresentado pelas inúmeras atividades humanas, havendo indivíduos que contribuíram de forma decisiva para os avanços da fotografia. Há os que contribuíram com o desenvolvimento dos elementos químicos, outros agregaram novos equipamentos e há ainda os que desenvolveram novos conceitos sobre a criação e o emprego da fotografia, como os fotógrafos que Freund (1995) e Sontag (2004) destacam:

Robert Fenton foi contratado para executar a documentação fotográfica da Guerra da Criméia em 1855, embora instruído de que deveria tirar as fotos de forma a não alarmar os familiares dos soldados lá presentes, mesmo assim é digno de nota devido ao pioneirismo do trabalho. $O$ tema guerra foi retratado mais fielmente pelo americano Mattew B Brady que, com iniciativa e economia própria, empregou vários fotógrafos, entre eles Thimothy O'Sullivan e Alexandre Gardner. Sua intenção era retratar com a maior realidade os horrores da guerra, a desolação dos campos provocada pelos combates, os incontáveis cadáveres, a miséria que resultava. $\mathrm{Na}$ época seu trabalho não alcançou os objetivos pretendidos e acabou na falência, apesar de suas fotos terem sido publicadas em muitos veículos.

Jacob A. Riis, jornalista do New York Tribune, de origem dinamarquesa, utilizava as fotos amadoras para dar veracidade aos seus artigos. Em 1890 publicou o livro Como vive a outra metade, que abalou a opinião pública. Esta obra contava com imagens das condições miseráveis em que se encontravam os imigrantes em Nova lorque. O sociólogo Lewis W. Hine seguiu os passos de Riis e, no período de 1908 a 1914 fotografou o trabalho infantil. O resultado provocou uma mudança nas legislações trabalhistas de então, promovendo melhoras na vida da classe trabalhadora. Era o início da fotografia como forma de crítica social.

A fotografia documental tem como expoentes Eugène Atget (1857-1927) e Heinrich Zille (1858-1929). O primeiro é um ator ambulante parisiense formado pelo Conservatório de Arte Dramática que, para garantir sua sobrevivência, em 1899 passou a fotografar as ruas, praças e monumentos de Paris, pessoas são raras em seus registros. Mal sabia ele que sem a intenção, inaugurava uma nova forma de fotografia. Suas fotos foram descobertas por Man Ray e André Breton, e publicadas na revista La Révolution Surréaliste, o que não impediu que morresse na miséria. Já o alemão Heinrich Zille (1858-1929), desenhista e litógrafo da Sociedade Fotográfica de Berlim, também se dedicou à fotografia documental, mas ao contrário do seu contemporâneo Atget, se dedicou a registrar os cidadãos berlinenses. Na Alemanha dos anos 30, uma geração de fotojornalistas seguiu a Zille. Eles acreditavam que o fotógrafo deveria utilizar a máquina como um "instrumento sensível" que revelava o referente (Freund, 1995).

A fotografia tomou rumo diferente a partir do italiano Disderi, que desenvolveu a patente da fotografia no formato "cartão de visitas". Com muita sagacidade ele inseriu a fotografia nas classes de poder aquisitivo mais baixo. Esse novo tamanho, e por consequência novo valor, possibilitou atender aos desejos dos gentios e a fotografia deixou de ser privilégio da realeza e das classes burguesas para atender ao pequeno burguês. Disderi não só atendeu um maior público como também se tornou o primeiro teórico desta área, com a publicação, em 1862, da obra "Estética da fotografia" (Freund, 1995).

Adolphe Braun é um nome que merece destaque pelo trabalho que empreendeu na reprodução de obras de arte. É pela fotografia que a obra de arte perderá sua aura e sairá do isolamento, tomando parte da vida da sociedade. A fotografia também permite que a obra de arte seja falsificada, dependendo da luz ou do enfoque que o fotógrafo utiliza, a obra pode ser totalmente descaracterizada (Freund, 1995).

A partir de 1900, o desenvolvimento de técnicas de fotocolografia (heliotipia, fotolitografia e fototipia) possibilitou o barateamento das reproduções, originando uma verdadeira indústria do cartão postal que inundaram os países europeus.

Em 4 de março de 1880 a fotografia - que teve seu início marcado pelo retrato individual e por toda simbologia que este retrato estava impregnado - inaugura uma nova forma de utilização, 
a fotografia aliada ao texto, a fotografia na imprensa. Com a publicação da foto "Shantytown", no Daily Graphic de Nova lorque, o enfoque dado antes ao indivíduo, vai ser destinado agora ao coletivo, surge o mass media, a partir deste momento a fotografia será adotada como um poderoso instrumento de propaganda e manipulação. Os detentores de poder econômico ou do poder político utilizarão as imagens conforme seus interesses (Freund, 1995).

Após a $1^{\text {a }}$ Guerra Mundial, vários fatores contribuíram para o desenvolvimento do fotojornalismo na Alemanha, como os avanços tecnológicos que possibilitavam a utilização de equipamentos mais ágeis e discretos; fotógrafos com educação aprimorada, freqüentemente filhos de famílias abastadas que perderam suas fortunas e mantiveram o status; o interesse dos fotógrafos, editores e redatores por novas experiências; o interesse pela vida privada de personalidades públicas. Com estes elementos contando a favor, surgem as revistas ilustradas, merecendo destaque a Berliner Illustrierte e a Müncher Illustrierte Presse, cada uma delas ultrapassando os 2 milhões de tiragens. O sucesso alcançado pelas revistas alemãs serviu de modelo para publicações de outros países (Freund, 1995).

A câmera Ermanox de fabricação alemã, produzida por Ernemann de Dresden no período de 1924 a 1931, considerada uma mini-câmera para a época e que propunha a retratar interiores e cenas noturnas sem a necessidade do uso de flash, apesar de utilizar placas de vidro para a captação das imagens, foi uma máquina muito utilizada pela imprensa alemã, contribuindo para o surgimento da fotografia cândida ou sincera cujo expoente foi "Herr Doktor" Erich Salomon (28 de abril de 1886 - 7 de julho de 1944). A Ermanox acabou por ser ultrapassada por câmeras de 35 milímetros como a Leica e a Contax ambas produzidas a partir de 1932, e que ainda possibilitavam o uso dos práticos rolos de filme, um enorme avanço para os fotógrafos da época.

Em uma época em que para se fotografar alguém havia a necessidade de montar toda uma parafernália de equipamentos, fazer com que o referente olhasse para a câmera e ficasse imóvel em sua pose, Salomon pretendia com suas fotos mostrar as celebridades políticas de então em situações comuns, comendo, dormindo, conversando, fumando. Sua proposta era captar a espontaneidade dos retratados, o que para a época era uma novidade.

O pioneiro das fotos "não-posadas" inaugura um novo estilo de fotografia. Suas fotografias sur- preendiam, apesar dos recursos existentes, ele ousava apresentando ângulos diferenciados, e conseguia fotografar sem que ninguém desse por sua presença. A discrição no momento do retrato era seu ponto forte, mas isso causava desconforto em seus retratados a ponto do premier francês Aristide Briand, chamá-lo de "o rei da indiscrição" (Freund, 1995).

O fotógrafo alemão marca o início de um novo perfil da profissão de fotojornalista: um indivíduo discreto que pode despercebidamente registrar flagrantes das autoridades em gestos casuais, colocando-os, assim, no patamar de meros mortais. Com a possibilidade de tirar fotografias instantâneas, mostrava os retratados em situações que não os favoreciam, sendo que a expressão candid photografy, traduzida para o português como fotografia cândida ou fotografia sincera, foi utilizada para descrever o trabalho de Salomon.

Salomon distinguia-se pela educação e cultura em pé de igualdade a de seus retratados, fazendo-se passar por um deles, com grande facilidade (1990, p. 22, 23).

Para Barthes, a foto deixa de ser meramente o objeto que é manipulado e visto. A conotação fotográfica (perceptiva, cognitiva e ideológica) é histórica e cultural, ou seja, o que leva a conhecer e a identificar os outros significados é justamente as experiências (ou a falta delas) que já houve com o tema abordado na imagem e também o contexto em que se esta inserido.

Através desse breve resgate da trajetória das tecnologias e das pessoas imbricadas na história da fotografia, torna-se minimamente apto para considerar que este objeto bidimensional produzido pela máquina fotográfica - que é a fotografia - seja perpassado em sua forma e em seu conteúdo por diversas influências existentes em nosso meio, desde o desenvolvimento tecnológico, a manipulação dos desejos da massa, até a necessidade de reconhecimento do próprio indivíduo. Pode ser considerado como uma expansão da memória, possuindo a propriedade e a emoção de voltar a tempos idos e longínquos, possibilitando recordações nítidas dos detalhes que o limitado cérebro humano, com o passar dos tempos, esquece.

Em face ao exposto, entende-se que as instituições de produção, guarda e disseminação de material imagético, e os profissionais estreitamente envolvidos com os processos de manipulação desse objeto necessitam de instrumental teórico e prático que os tornem habilitados para lidar de forma competente com as peculiaridades do documento iconográfico, caso contrário a explosão fotográfica dos dias atuais não resulta- 
ra em nada além do que uma montanha de imagens, sem finalidade ou identidade definidas.

\section{Ciência da Informação e Arquivologia}

Para a consecução do trabalho proposto procurou-se maiores aprofundamentos na teoria da área de Ciência da Informação, e o resultado foi a percepção de que as pesquisas ainda engatinham se comparadas às desenvolvidas por ciências tidas clássicas como a Filosofia, estabelecida há milênios e considerada por estudiosos e pesquisadores como o marco inicial do pensamento racional do ser humano, a grande mãe das ciências; a Matemática, na qual não há uma projeção em tempo, contudo, sabe-se que os signos matemáticos existiram antes mesmo que os signos lingüísticos; mesmo se comparada as ciências modernas, como a Sociologia, uma jovem ciência de aproximadamente duzentos anos, vê-se que a Ciência da Informação ainda tem um longo percurso em busca da consolidação. Para tanto é necessário a discussão de suas práticas, conceitos, abordagens e tendências. A seguir traça-se o esboço de uma reflexão epistemológica.

Ao resgatar alguns traços da história da Ciência da Informação obtém-se um percurso de poucas décadas, nos quais esse breve tempo de existência se ressente de um corpus teórico e carece de atenção por parte dos profissionais que estão se estabelecendo nessa área, em prol do estabelecimento do objeto de estudo como também da metodologia característica dessa nova ciência.

A ciência, no período intitulado moderno, era baseada no modelo cartesiano, tido como único objeto de estudo e método, resultando em divisão do conhecimento em compartimentos distintos e tendo a finalidade de conhecer a verdade totalizadora, predominando a distância entre o sujeito e seu objeto de estudo: nós, aqui, as transformações, lá fora (Santos, 1999, p. 18).

São inúmeras as transformações vividas pela humanidade nos últimos séculos, desde as origens das ciências clássicas atravessando as ciências modernas e chegando ao momento contemporâneo com uma economia globalizada, cujos interesses já não mais se traduzem na busca por mão de obra barata como em outros momentos históricos, mas sim, hoje o foco está na capacidade dos indivíduos gerarem conhecimento e, principalmente, na possibilidade desse conhecimento ser estratégico, sendo que os princípios da Ciência Moderna não podem mais dar conta do que ocorre no mundo globalizado.
Hoje, o momento é pós-moderno e caracterizado por vários "pós" que apesar de obviamente ter o intuito de indicar superações, como o pósHolausto, pós-industrial, pós-humanista, póscultural, contraditoriamente, a preposição também pode imprimir um tom de exaustão ou decadência como pode ser notado em textos de Charles Newman, Irving Howe e Arnold Toynbee que referem ao pós-modernismo como significado de declínio. A visão positiva sobre o pós-modernismo é mais recente, nas obras de Leslie Fiedler, Ihab Hassan, Jean-François Lyotard. Para esses autores, o pós-moderno é considerado o herdeiro bem sucedido do decadente modernismo (Connor, 1996, p. 57).

A palavra pós-modernismo refere-se em geral a uma forma de cultura contemporânea, enquanto o termo pós-modernidade alude a um período histórico específico. Pós-modernidade é uma linha de pensamento que questiona as noções clássicas de verdade, razão, identidade e objetividade, a idéia de progresso ou emancipação universal, os sistemas únicos, as grandes narrativas ou os fundamentos definitivos de explicação. Contrariando essas normas do iluminismo, vê o mundo como contingente, gratuito, diverso, instável, imprevisível, um conjunto de culturas ou interpretações desunificadas gerando certo grau de ceticismo em relação à objetividade da verdade, da história e das normas, em relação às idiossincrasias e a coerência de identidades. Essa maneira de ver como sustentam alguns, baseia-se em circunstâncias concretas: ela emerge da mudança histórica ocorrida no Ocidente para uma nova forma de capitalismo para o mundo efêmero e descentralizado da tecnologia, do consumismo e da indústria cultural, no qual as indústrias de serviços, finanças e informação triunfam sobre a produção tradicional, e a política clássica de classes cede terreno a uma série difusa de "políticas de identidade". Pósmodernismo é um estilo de cultura que reflete um pouco essa mudança memorável por meio de uma arte superficial, descentrada, infundada, autoreflexiva, divertida, caudatária, eclética e pluralista, que obscurece as fronteiras entre a cultura "elitista" e a cultura "popular", bem como entre a arte e a experiência cotidiana. O quão dominante ou disseminada se mostra essa cultura - se tem acolhimento geral ou constitui apenas um campo restrito da vida contemporânea - é objeto de controvérsia. (Eagleton, 1998, p. 7)

Vê-se que as mudanças profundas e rápidas na sociedade (como a da China, por exemplo) podem ser creditadas aos próprios elementos nela imbricados, a saber: a economia globalizada e globalizante; as tecnologias empregadas nos mais diversos campos de atuação; as políticas nacionais e internacionais; a não preservação de costumes e culturas regionais e mais recentemente inclui-se os fatores climáticos que, como conseqüência de ações imediatistas do homem, vem dando a resposta para os abusos 
cometidos. Observa-se que em razão dessa velocidade em muitos momentos a teoria não acompanha as mudanças da realidade, realidade esta que parece auto-teorizar-se (Santos, 1999).

O contexto atual, caracterizado como pósmoderno influi sobre inúmeros profissionais das mais diversas áreas, mas principalmente no tocante ao profissional que lida com a informação devido ao novo status que ela representa, como bibliotecários e arquivistas.

O momento da arquivologia também é de redimensionamento, a área passa por um processo re-estruturador de espaços compreendidos nas esferas científica, social e tecnológica, é um momento de crise ao mesmo tempo uma possibilidade de evolução para o campo (Jardim, 1998, p. 1).

Quando o assunto é arquivística, estão imbricados no termo os arquivos, os arquivistas e a arquivologia, embora os três conceitos ainda careçam de um consenso, Jardim (1998) adota a definição de arquivista como "produtor do conhecimento". Segundo o autor existem correntes divergentes na arquivologia: a mais conservadora entende que a arquivologia se volta aos arquivos históricos, na qual a gestão de documentos é distinta da arquivística. Concorrendo com outra corrente que acredita na integração e integridade de gestão de documentos e arquivologia, e que o arquivo só tem função quando utilizado, disseminado.

A visão hegemônica internacional da arquivologia é que esta seria uma disciplina, um campo auxiliar da história, ou no máximo um método.

Contudo, Thomassem (1996 apud Jardim, 1998, p. 3) afirma que

entre as mudanças provocadas pelos avanços tecnológicos, a mais estimulante é que a arquivologia deixou de ser uma ciência auxiliar da história para converter-se em uma disciplina autônoma no campo das ciências da informação."

Ainda segundo o autor, a revolução tecnológica, juntamente com as transformações econômicas das últimas décadas afetaram de forma contundente os modos de produção, uso e transferência da informação, o que deixa evidente alguns conflitos na arquivologia no que tange a tópicos inter-relacionados como: a) funcionamento de serviços de informação arquivística; b) identidade profissional do arquivista; c) produção de conhecimento arquivístico (Jardim, 1998).

Para que se entenda o arquivista como "produtor de conhecimento" é necessário aprofundar nestes conflitos e assim poder, com proprieda- de, pensar a arquivologia como disciplina. Através de Jardim (1998), observa-se correntes divergentes para a compreensão da arquivologia, e conhecê-las é importante, pois se trata de uma discussão epistemológica.

O que hoje se caracteriza por uma sociedade da informação força a arquivologia a sair da idade empírica (do saber fazer) e entrar para a idade científica (produzir conhecimento) (Delmas, 1992, apud Jardim, 1998, p. 2).

Para Delmas (1990 apud Jardim, 1998, p. 2).) a arquivologia é

ciência que estuda os princípios e os procedimentos metodológicos empregados na conservação dos documentos de arquivo, permitindo assegurar a preservação dos direitos, dos interesses, do saber e da memória das pessoas físicas e morais.

Heredia Herrera considera que a arquivística $(1991,29)$

es la ciencia de los archivos, no de los documentos, aunque en última instancia éstos sean el producto integrante de aquéllos. Como tal se ocupará de la creación, historia, organización y servicio de los mismos a la Administración y a la Historia, en definitiva a la Sociedad.

Para Heredia Herrera (1991), a arquivística conta com um objeto, um método e uma linguagem ainda que por consolidar (1991, p. 31-32). Borga Aguinagalde (1991) diverge de Heredia Herrera, para ele não está evidente a existência de uma ciência arquivística, pois seria necessário contar com uma problemática própria e um conjunto de questões e teorias referenciais, ainda sob seu ponto de vista, falte um consenso sobre o objeto, os métodos, a finalidade e a terminologia (Borga Aguinagalde, 1991, p. 2).

Contraditoriamente a canadense Couture (1992), considera a arquivologia como uma disciplina no mais completo sentido do termo, com uma visão integradora sobre a área.

Couture (1992, p. 85 apud Jardim, 1998, p. 2) entende que a arquivologia

cobre o conjunto de princípios e métodos que regem a criação, a avaliação, a aquisição, a classificação, a descrição, a difusão e a conservação de arquivos [...]. Não é mais suficiente conservar os arquivos, é preciso difundi-los.

Ainda segundo proposição da autora há alguns requisitos para que se possa reconhecer o lugar e o estatuto da arquivologia para que seja reconhecida como ciência e para que se torne uma ciência conhecida (Couture 1992 apud Jardim, 1998, p. 2):

que a área estruture adequadamente suas atividades e delimite seu campo de atividade; 
que se libere da tutela à história e à administração;

que busque a sua autonomia para que se torne uma verdadeira disciplina;

que desenvolva relações interdisciplinares com diversos campos como a informática;

a documentação, a biblioteconomia, a ciência da informação, a antropologia, a sociologia, a lingüística e, é claro, a história e a administração;

que reforce suas bases por meio da pesquisa e da formação profissional.

No Congresso de 1988, em Paris, o tema discutido foi "Os documentos produzidos pelas novas tecnologias da informação"; no Congresso de 1992, em Montreal, o assunto foi "Atuação do arquivista na era da informação"; no Congresso de 1996, em Beijing, a temática girou em torno d' "Os arquivos ante o final do século: balanço e perspectiva". Nota-se que a comunidade arquivística internacional, nesses doze anos que separaram os congressos, discutiram os documentos, os arquivistas e os arquivos, fato que reflete que a arquivologia e sua epistemologia, poderiam ser encontradas em discussões periféricas, mas não foram o foco central de nenhuma delas. No Congresso de Beijing, Cook (1996) expõe a necessidade de estabelecer a trajetória histórica e intelectual da profissão arquivística e dos arquivos, mas ignora a importância epistemológica da área para que seja possivel configurar como área do conhecimento (Jardim, 1998, p. 3).

Luigi (1996, apud Jardim, 1998, p. 3) nota que a arquivologia evoluiu e que essa evolução denota que o arquivista deixou o trabalho de artesão altamente qualificado para inserir-se em uma profissão que precisa de bases teóricas e cunho científico para que possibilite a entrada dos arquivistas nesse novo mercado de trabalho. A que corpus teórico esta preparação científica estaria sujeita?

Percebe-se posições distintas entre os teóricos acima relacionados, mas o que toda essa discussão reflete é a ausência de maiores e mais profundas discussões "sobre arquivologia como campo do conhecimento científico e sua inserção nos modelos informacionais atuais e emergentes (Jardim, 1996, p. 3).

Assim como em Ciência da Informação, a Arquivologia carece de um consenso sobre os termos técnicos pertinentes ou utilizados pela arquivística. Escassa publicação da área frente a outros campos do conhecimento, ou seja, os arquivistas ainda produzem pouco conhecimento científico, estão voltados para a pragmática e aplicação dos fundamentos/preceitos arquivísticos.
Contudo, e apesar de carecer de discussões na área epistemológica, a prática arquivística há muito vem se aperfeiçoando e dinamizando o tratamento documental, contribuindo de forma contundente com seus princípios fundamentais, essencialmente nos documentos ditos probatórios, reflexos de uma função e com valores legais.

Observa-se que arquivos, públicos ou privados, seguem os princípios fundamentais da arquivologia, mencionados a seguir.

\subsection{Respeito aos Fundos}

Schellenberg (2006) discorre sobre a origem das diferentes correntes de entendimento da arquivologia e todas estão estreitamente vinculadas ao contexto em que a instituição arquivo foi originada em países como a França, a Inglaterra, ou nos Estados Unidos. Independente da origem e da linha de pensamento seguida por cada país, há fundamentos comuns que permeiam todas as correntes arquivísticas. O principal fundamento encontrado em todas as linhas é o respeito pelos fundos ou princípio de proveniência.

É à França que se credita o fato que proporcionou o grande avanço na teoria arquivística: a partir de uma portaria estabelecida por Guizot (2) em 08 de agosto de 1839, complementada por circular do Conde Duchatel, em 24 de abril de 1841 . No texto havia a orientação para que os arquivos incorporados aos Archives Nacionales fossem ordenados pelos fundos de origem e não pelos esquemas de classificação prédeterminados (Schellenberg, 2006, p. 241).

As diretrizes mencionadas deram origem à formulação do princípio básico do respeito aos fundos, que reza que os documentos oriundos de uma instituição, indivíduo ou família, serão mantidos agrupados, consistindo-se em fundos. $E$, por sua vez, os documentos pertencentes a esses fundos, deverão ser arranjados por assunto, por ordem cronológica, geográfica e alfabética. Esse princípio básico aperfeiçoado na Prússia tornou-se o princípio da proveniência (Schellenberg, 2006, p. 243).

\subsection{Fases do Arquivo}

Ao visitar pela primeira vez a empresa, com a finalidade de desenvolver o projeto para apresentação no Programa de Pós-Graduação em Ciência da Informação da Unesp, Campus de Marília, SP, Brasil, constatamos que, mesmo sem conhecer os princípios arquivísticos de idade dos documentos, descritos por Heredia Herrera (1991) (3), no caso do arquivo empresa- 
rial estudado, a teoria das três idades é aplicada intuitivamente da seguinte forma:

Os álbuns são armazenados em três locais distintos: no depósito recém criado ao lado do edifício principal, foi destinado para armazenamentos de novos álbuns; há um grande espaço de armazenagem junto ao edifício administrativo, onde armazenam os álbuns que ainda podem representar interesse para algum cliente; há, ainda, a existência de um terceiro depósito de álbuns que não apresentam mais interesse comercial.

Com essa verificação, pode-se conferir a validade de tal fundamento teórico (Bellotto, 2004, p. 30):

Perpassando por todo o ciclo vital e, portanto, pelos três tipos-idades dos arquivos, a função arquivística é hoje considerada um todo indivisível, ao contrário da conceituação obsoleta de tomar-se, de um lado, a administração de documentos e, de outro, o arranjo e a descrição de fundos como atividades estanques e desvinculadas uma da outra. Há toda uma gama de tarefas sucessivas que cabe ao arquivista desempenhar ao longo das três fases bem definidas: o controle dos arquivos em formação, a destinação e a custódia definitiva.

\section{Material e métodos}

Em razão do exposto, para a execução do trabalho optou-se pela pesquisa de campo, pois baseia-se na observação dos fatos tal como ocorrem na realidade. Para acesso ao material que possibilite o desenvolvimento de pesquisa qualitativa, pretende-se utilizar o estudo de caso, pois viabiliza o estudo profundo e exaustivo de um único objeto de estudo, de maneira que permite um amplo e detalhado conhecimento do objeto em questão.

Em Sainsaulieu e Kirchner (2006) corrobora-se a escolha da metodologia de estudo de caso já que é mais empregada para se conhecer o universo das empresas brasileiras.

\subsection{Campo de Observação}

O estudo tem como recorte teórico o arquivo fotográfico privado da Empresa Multicolor, acervo com aproximadamente 100.000 unidades de álbuns, o que equivale à preservação de vinte $\mathrm{e}$ três anos de existência das atividades da empresa fotográfica.

$O$ arquivo do gênero iconográfico é especializado em álbuns fotográficos, é centralizado, pois as atividades de protocolo (4) são exercidas por um funcionário apenas, mas quanto ao depósito há possibilidade de descentralização como solução ao espaço restrito. Seu conteúdo é reser- vado, pois não é de interesse da empresa que o público em geral tenha conhecimento dos documentos arquivados. Para seu arranjo utilizase o sistema indireto numérico simples.

Há três anos, a empresa vem se adequando às tecnologias e ao mercado que exigem o trabaIho com imagens produzidas digitalmente. $O$ Gerente Comercial da empresa é o responsável pelo arquivo e se mostra afeito à proposta de levar conhecimentos teórico-metodológicos e pragmáticos que embasem as rotinas desempenhadas por funcionário sob sua tutela, possibilitando dessa forma que instaure-se um intercâmbio entre a realidade de um arquivo fotográfico de grandes dimensões e com finalidade comercial e o ambiente acadêmico.

\subsection{Sujeitos da Pesquisa}

Os sujeitos da pesquisa compreendem:

- Diretores da Empresa, pois são deles que emanam os pragmatismos que acabam por influenciar drasticamente as rotinas e o desenvolvimento ou não de políticas adotadas pelo arquivo;

- Funcionário responsável pelo arquivamento e pela recuperação dos documentos do arquivo, por concentrar o capital intelectual da empresa e do arquivo dos últimos 13 anos;

- Usuários do arquivo, no caso o grupo formados pelos vendedores da empresa e demais funcionários, já que são eles que mais se ressentem das dificuldades no momento de encontrar a informação desejada.

\subsection{Técnicas e Instrumentos}

Optou-se por utilizar como instrumentos de pesquisa a observação, pois "é feita sobre tudo aquilo que não é dito, mas pode ser visto e captado por um observador atento e persistente" (Minayo, 2007, p. 63).

Em complemento aplicaremos a entrevista que "tem como matéria-prima a fala dos sujeitos da pesquisa" (Minayo, 2007, p. 63). Utilizaremos, para tanto, a pesquisa aberta ou em profundidade, que permite que o entrevistado fale abertamente sobre o tema e responda às perguntas do pesquisador livremente.

\subsection{Análise de resultados}

Quanto à análise dos dados optou-se pelo método de abordagem indutivo, partindo dos dados coletados para a elaboração de um relatório que viabilize a transmissão clara e objetiva das informações resultantes do estudo, possibilitando ao leitor generalizações com outros casos em 
que o objeto de estudo tenha as mesmas características.

\section{Considerações Finais}

Em um primeiro contato com a empresa, visando à apresentação da proposta e autorização para continuidade do projeto, a pesquisadora responsável foi recebida pelo Gerente Comercial, Senhor João Luís Seiscentos, responsável pelo arquivo da empresa. A possibilidade de um estudo acadêmico com o intuito de trabalhar a organização da informação em arquivo empresarial do ramo fotográfico veio ao encontro das necessidades já detectadas pelo Senhor João Luís, e sendo assim, foi bem recebida.

Ele compreendeu que o estudo acadêmico possibilita 0 acesso a conhecimentos teóricometodológicos e pragmáticos que embasem as rotinas desempenhadas por funcionários sob sua tutela, oportunizando uma comunicação e futuro intercâmbio entre a realidade de um arquivo fotográfico empresarial de grandes dimensões com finalidade comercial e o ambiente acadêmico.

Notou-se que o arquivo está dividido fisicamente em três partes, mas essa divisão não se dá através de percepção conceitual e sim feita somente por questões de espaço, que é restrito. O fluxo de produção é superior à saída, o que ocasiona uma necessidade de espaço cada vez maior. Há perspectiva por parte do Sr. João Luis Seiscentos que haja uma construção específica para o arquivo, aonde todos os álbuns possam ser alojados de uma forma definitiva.

O acervo estudado carece de diagnóstico, pois, a estrutura apresenta-se comprometida pela grande capacidade de produção da empresa, em contrapartida não há manuais ou políticas estabelecidas, inexiste uma tabela de temporalidade, ou instrumentos de pesquisa visando à otimização de recursos técnicos e humanos.

Discutiu-se a necessidade de descarte periódico de álbuns diante do não interesse por parte dos clientes. Atualmente esse desbaste é feito de três em três meses, ou mediante o tempo disponível do Diretor Comercial, responsável direto pelo arquivo. Este assunto foi responsável por introduzir o conceito de tabela de temporalidade na discussão, no qual foi vista pelo Diretor de forma positiva. Pode-se perceber que há um grande fluxo de informação neste espaço empresarial, que demanda organização.

Quanto às fichas cadastrais que suportam as informações sobre os álbuns sabe-se que é originada no momento de identificação do formando, mas durante esse processo pode acontecer falhas. Percebe-se que há várias deman- das para essas fichas, sendo que, além do arquivo, o Departamento de Vendas têm grande necessidade de organização e acesso a elas.

Há necessidade de efetuar um organograma para compreender os vários departamentos da empresa e a confecção de um fluxograma para entender todas as rotinas pertinentes ao arquivo no tocante aos álbuns e principalmente à circulação das fichas. Percebe-se uma grande preocupação com essas fichas, pois somente elas possuem todos os dados para recuperação da informação, no caso da empresa a recuperação da informação significa a recuperação do álbum em meio a uma grande massa de documentos.

A empresa promove ações que visam a sustentabilidade das atividades fins, como, por exemplo, a oferta de um curso preparatório para fotógrafos, sendo que todos são contratados como free-lancers em momentos de maior concentração de eventos, e os que se sobressaem em habilidades e competências acabam por ser contratados como fotógrafos fixos da empresa.

Há uma nítida dificuldade em localizar mão de obra para trabalhar com a informação pertinente ao arquivo. Os funcionários não conhecendo a importância de suas ações em prol da organização da informação empresarial acabam por não apresentar o comprometimento esperado com a execução das rotinas, o que torna as atividades desempenhadas, principalmente a recuperação da informação, um trabalho moroso e sofrido.

\section{Notas}

(1) Membros da seita Shindo-Remmei que não admitiam a veracidade da rendição do Japão no final da Segunda Guerra Mundial, mais informações ver a obra "Corações Sujos", de Fernando Moraes.

(2) Na ocasião ministro da Instrução Pública (18321839) e posteriormente Primeiro Ministro da França (1840-1848) (Schellenberg, 2006, p. 243).

(3) La primera etapa o edad: es de circulación y tramitación por los canales y cauces normales en busca de respuesta o solución para el asunto que se ha iniciado. La documentación forma parte de los archivos sectoriales, corrientes o de gestión. Está cerca del funcionario responsable de su tramitación, en su mesa, en archivadores, en armarios al alcance de su mano para su manejo frecuente. La segunda etapa o edad: en ella, una vez recibida la respuesta o solución al asunto empezado, el documento o expediente que lo testimonia ha de seguir siendo guardado, pudiendo ser objeto de consulta o de antecedente, pero no con la frecuencia que en la primera etapa. La tercera etapa o edad: el documento asume un valor permanente y se ceñirá a ser consultado por su valor cultural e informativo con fines de investiga- 
ción. Su archivación y conservación serán definitivas (Heredia Herrera, 1991, p. 173)

(4) Protocolo: denominação atribuída aos setores encarregados de atividades de recebimento, registro, distribuição, movimentação e expedição dos documentos (Paes, 2004, p. 27).

\section{Referências}

Barthes, Roland (1984). A câmara clara. Rio de Janeiro: Nova Fronteira, 1984.

Barthes, Roland (1990). O óbvio e o obtuso: ensaios críticos III. Trad. Lea Novaes. Rio de Janeiro: Nova Fronteira, 1990.

Benjamin, Walter (1993). A obra de arte na era de sua reprodutibilidade. // Benjamin, Walter. Obras escolhidas. São Paulo: Brasiliense, 1993.

Connor, Steven (1996). Cultura pós-moderna: introdução às teorias do contemporâneo. Tradução Adail Ubirajara Sobral e Maria Stela Gonçalves. 3. ed. São Paulo: Loyola, 1996.

Eagleton, Terry (1998). As ilusões do pós-modernismo. Tradução Elisabeth Barbosa. Rio de Janeiro: Jorge Zahar, 1998.

Freund, Gisele (1995). Fotografia e sociedade. 2. ed. Lisboa: Veja, 1995.

Heredia Herrera, Antônia (1991). Archivística general. Teoría y práctica. 5. ed. actual. aum. Sevilla: Diputación Provincial de Sevilla, 1991.

Jardim, José Maria (1998). A produção de conhecimento arquivístico: perspectivas internacionais e o caso brasileiro (1990-1995). // Ci. Inf. [online]. 27:3 (1998). http://www.scielo.br/pdf/ci/v27n3/27n3a01.pdf (2009-0123)

Minayo, Maria Cecília de Souza (Org.); Deslandes, Suely Ferreira; Gomes, Romeu (2007). Pesquisa social: teoria, método e criatividade. 25 ed. rev. ampl. Petrópolis: Vozes, 2007.

Paes, Marilena Leite (2004). Arquivo: teoria e prática. 3 ed. rev. ampl. Rio de Janeiro: FGV, 2004.

Sainsaulieu, R.; Kirschner, A. M. (2006). Sociologia da empresa: organização, poder, cultura e desenvolvimento no Brasil. Rio de Janeiro: DP\&A, 2006.

Sánchez Vigil, Juan Miguel (2002). Automatización de los archivos fotográficos. Modelos de fin de siglo: Oronoz $Y$ Scala. // Biblios. 13 (jul./set. 2002) 1-13.

Santos, Boaventura Souza (1999). Pela mão de Alice: o social e o político na pós-modernidade. 6 ed. São Paulo: Cortez, 1999.

Schellenberg, Theodore R. (2006). Arquivos Modernos: princípios e técnicas. 6. ed. Rio de Janeiro: FGV, 2006.

São Paulo (Estado). Secretaria Do Emprego E Relações Do Trabalho (2001). Aprendendo a apreender com a comunidade do município de Tupã. São Paulo: Fundunesp, 2001.

Sontag, Susan (2004). Sobre fotografia. São Paulo: Companhia das Letras, 2004. 